Case Reports in
Gastroenterology
Case Rep Gastroenterol 2021;15:62-69

DOI: 10.1159/000510919

Published online: January 25, 2021
(C) 2021 The Author(s)

Published by S. Karger AG, Basel www.karger.com/crg

This article is licensed under the Creative Commons Attribution-NonCommercial 4.0 International License (CC BY-NC) (http://www.karger.com/Services/OpenAccessLicense). Usage and distribution for commercial purposes requires written permission.

\title{
Next-Generation Sequencing for Non-Ampullary Duodenal Carcinoma Suggesting the Existence of an Adenoma-Carcinoma Sequence
}

\author{
Tsubasa Yoshida ${ }^{a, b} \quad Y^{a}$ ohei Kojima ${ }^{c, d} \quad$ Ryusuke Shimada ${ }^{a}$ \\ Hidesato Tanabe $^{a}$ Koichi Tabei $^{a}$ Osamu Yanagida ${ }^{c}$ Takashi Nikaido $^{\mathrm{e}}$ \\ Kouki Ohtsuka $^{f}$ Hiroaki Ohnishi $^{f}$ Nobutsugu Abe $^{d}$ \\ Tadakazu Hisamatsu ${ }^{b}$ Shinichi Takahashi ${ }^{a, b}$ \\ ${ }^{a}$ Department of Internal Medicine, Kosei Hospital, Tokyo, Japan; ${ }^{b}$ Department of \\ Gastroenterology and Hepatology, Kyorin University School of Medicine, Tokyo, Japan; \\ 'Department of Surgery, Kosei Hospital, Tokyo, Japan; dDepartment of \\ Gastroenterological and General Surgery, Kyorin University School of Medicine, \\ Tokyo, Japan; 'Department of Pathology, Kosei Hospital, Tokyo, Japan; fDepartment of \\ Laboratory Medicine, Kyorin University School of Medicine, Tokyo, Japan
}

\section{Keywords}

Familial adenomatous polyposis - Duodenal cancer - Adenoma-carcinoma sequence . Next-generation sequencing

\begin{abstract}
Duodenal tumors with a sporadic adenoma-carcinoma sequence are extremely rare. For such clinically suspected cases without a specific family history, performing a comprehensive gene search is important to understand the germline mutation background. We present a 68-yearold woman without a genetic or familial history of familial adenomatous polyposis (FAP), Peutz-Jeghers syndrome, or Lynch syndrome who presented to Kosei Hospital, Japan, with exertional dyspnea induced by abdominal pain lasting 3 weeks. A duodenal tumor was suspected by contrast-enhanced computed tomography. Esophagogastroduodenoscopy showed a lesion accompanied by a white microprotuberance on the descending part of the duodenum
\end{abstract}

Tsubasa Yoshida
Department of Internal Medicine
Kosei Hospital
$2-25-1$, Wada, Suginami-ku, Tokyo 166-0012 (Japan)
daigakurennraku@yahoo.co.jp




\section{Case Reports in Gastroenterology}

Case Rep Gastroenterol 2021;15:62-69 DOI: 10.1159/000510919

(c) 2021 The Author(s). Published by S. Karger AG, Basel www.karger.com/crg

Yoshida et al.: Next-Generation Sequencing for Non-Ampullary Duodenal Carcinoma Suggesting the Existence of an Adenoma-Carcinoma Sequence

opposite the papilla, with a giant ulcerative lesion at the center of the white lesion. Biopsy revealed a low-grade adenoma, high-grade adenoma, and adenocarcinoma. Immunohistochemical analysis of the adenoma and adenocarcinoma showed Ki-67, p53, cytokeratin 20, caudal-type homeobox 2, and carcinoembryonic antigen positivity and cytokeratin 7 negativity. The findings suggested the presence of an adenoma-adenocarcinoma sequence in duodenal carcinoma. However, in the mutational analysis using next-generation sequencing, c.4348C > T (p.Arg1450Ter) mutation in APC was detected in all normal mucosal, adenoma, and carcinoma tissues. This mutation is common in FAP patients. Even if the presence of an adenoma-adenocarcinoma sequence in duodenal carcinoma is suggested in cases without a familial FAP history, as in this case, genetic analysis may reveal FAP. Thus, performing a comprehensive genetic analysis of duodenal carcinoma patients with a possible adenoma-carcinoma sequence is necessary to explore their genetic background.

\section{Introduction}

The multistep theory of genetic mutation associated with the colorectal adenoma-carcinoma sequence is well documented $[1,2]$. The adenoma-carcinoma sequence has been proposed to be established in ampullary duodenal carcinomas [3]. However, it is unclear whether the adenoma-carcinoma sequence also occurs in non-ampullary duodenal carcinomas. Relatively few studies have investigated morphological changes associated with the adenoma-carcinoma sequence in gastrointestinal carcinomas $[4,5]$.

Duodenal carcinoma in familial adenomatous polyposis (FAP) arises from adenomas. Differentially expressed genes in the duodenal adenoma-carcinoma pathway have been identified in murine FAP models; however, similar data in patients with FAP are limited [6]. Here, we report about a patient without a familial history of FAP in whom a histopathological finding suggestive of the adenoma-carcinoma sequence was obtained from the biopsy results of a bulging lesion in the duodenum, and the lesion was identified as an APC germline mutation by a genetic analysis.

\section{Case Report}

A 68-year-old woman without a genetic or familial history of FAP, Peutz-Jeghers syndrome, or Lynch syndrome presented to Kosei Hospital, Japan (Nakano, Japan) with exertional dyspnea induced by abdominal pain lasting 3 weeks. Contrast-enhanced computed tomography showed irregular wall thickening in the descending part of the duodenum (Fig. 1), and a heterogeneous contrast effect was observed at the same site. Multiple low-density areas were observed in the liver, suggesting a neoplastic lesion. Blood test results indicated that her carcinoembryonic antigen level was $73.5 \mathrm{ng} / \mathrm{mL}$ and her carbohydrate antigen $19-9$ level was $112.2 \mathrm{U} / \mathrm{mL}$, both of which exceeded the normal limits.

Esophagogastroduodenoscopy showed a lesion accompanied by a white microprotuberance on the descending portion of the duodenum opposite the papilla and a giant ulcerative lesion at the center of the white lesion. The range of the tumor is shown in Fig. 2 (dotted red line). The lesion site was different from that of the papilla, and it was judged to not be a papillary-derived lesion.

\section{Karger'=}




\section{Case Reports in Gastroenterology}

Case Rep Gastroenterol 2021;15:62-69

DOI: $10.1159 / 000510919$

(c) 2021

www.karger.com/crg

Yoshida et al:: Next-Generation Sequencing for Non-Ampullary Duodenal Carcinoma Suggesting the Existence of an Adenoma-Carcinoma Sequence

Given that ulcerative lesions exhibiting white elevated microprotrusions were observed, they were considered to be consecutive lesions. Biopsies of three consecutive lesions were performed (Fig. 2; red dotted lines). Biopsy No. 1 sample was taken from the white microprotuberance around the ulcer. Biopsy No. 2 sample was taken from the surrounding ridges accompanied by redness of the ulcer. Biopsy No. 3 sample was taken from the top of the ulcerative lesion to the contralateral side of the papilla.

\section{Immunohistochemical Analysis}

Biopsy samples were immunohistologically analyzed for the expression of p53 and Ki-67 (Fig. 3a). In lesion No. 1, p53- and Ki-67-expressing epithelial cells primarily formed a regular pattern at the base of the crypts. A higher proportion of Ki-67-expressing epithelial cells was found in lesion No. 2, and the cells were distributed in an irregular pattern. p53 was strongly expressed in epithelial cells, and the cells were regularly arranged. The proportion of Ki-67expressing epithelial cells was the highest in lesion No. 3, and lesion No. 3 strongly expressed p53.

Based on pathology and immunohistochemistry, lesion No. 1 was considered to be a mildto-moderate tubulovillous adenoma, whereas lesion No. 2 appeared to be a moderate-to-severe tubulovillous adenoma. Lesion No. 3 had both severe tubulovillous adenoma and wellto-poorly differentiated adenocarcinoma components. The tubular adenocarcinoma tested negative for cytokeratin (CK) 7 and positive for CK20 and caudal-type homeobox 2 (Fig. 3b). Based on the histopathological results, the patient was diagnosed as having a duodenal carcinoma and multiple liver metastases. Fluid replacement was performed for anorexia, which was considered to be because of the duodenal carcinoma. She was transferred to another hospital for chemotherapy after the diagnosis.

Immunohistochemistry was performed for human mutL homolog (MLH) 1, MSH2, MSH6, and postmeiotic segregation increased (PMS) 2 in all biopsy samples (Fig. 3c). The expression of MLH1, MSH2, MSH6, and PMS2 was observed in all tissues. Therefore, it was concluded that the patient did not have Lynch syndrome.

Based on the endoscopic and histopathological findings, the present case was considered to be a duodenal adenocarcinoma resulting in a duodenal carcinoma. We considered this to be a rare case that suggested an adenoma-carcinoma sequence in the duodenum. Therefore, we performed additional genetic tests to confirm the presence of an adenoma-carcinoma sequence in the duodenum.

\section{Mutational Analysis by Next-Generation Sequencing}

Genes were extracted from the cells of the normal mucosa, adenomas, and adenocarcinomas, and next-generation sequencing was performed for 50 genes. Mutational hotspots of 50 oncogenes and tumor-suppressor genes were analyzed using Ion AmpliSeq Carcinoma Hotspot Panel v2 (Life Technologies, Carlsbad, CA, USA) on an Ion Torrent Personal Genome machine (Ion PGM, Life Technologies). The following genes were analyzed: $A B L 1, A K T 1, A L K$, $A P C, A T M, B R A F, C D H 1, C D K N 2 A, C S F 1 R, C T N N B 1$, EGFR, ERBB2, ERBB4, EZH2, FBXW7, FGFR1, FGFR2, FGFR3, FLT3, GNA11, GNAS, GNAQ, HNF1A, HRAS, IDH1, JAK2, JAK3, IDH2, KDR, KIT, KRAS, MET, MLH1, MPL, NOTCH1, NPM1, NRAS, PDGFRA, PIK3CA, PTEN, PTPN11, RB1, RET, SMAD4, SMARCB1, SMO, SRC, STK11, TP53, and VHL.

The c.4348C >T (p.Arg1450Ter) mutation in APC was detected in all normal mucosal, adenoma, and carcinoma tissues. This mutation is common in FAP patients, and it is a pathogenic mutation $[7,8]$.

\section{Karger'=}




\section{Case Reports in Gastroenterology}

\begin{tabular}{l|l}
\hline Case Rep Gastroenterol 2021;15:62-69 \\
\hline DOI: 10.1159/000510919 & $\begin{array}{l}\text { @ 2021 The Author(s). Published by S. Karger AG, Basel } \\
\text { www.karger.com/crg }\end{array}$ \\
\hline
\end{tabular}

Yoshida et al.: Next-Generation Sequencing for Non-Ampullary Duodenal Carcinoma Suggesting the Existence of an Adenoma-Carcinoma Sequence

The c.659A $>\mathrm{G}$ (p.Tyr220Cys) mutation in TP53 was detected in patients with carcinomas only as somatic mutation. No KRAS mutations were found in any samples. Based on this, this case was confirmed to be a duodenal carcinoma occurring in an FAP patient with a germline APC mutation.

\section{Outcome and Follow-Up}

Distant metastases including liver metastases were recognized as unresectable factors. The patient was treated with chemotherapy at the hospital to which she was transferred. As first-line therapy, she was treated with 5-FU/l-LV/oxaliplatin (FOLFOX). The anti-tumor effect of FOLFOX was limited, and thus, she was treated with low-dose FP (cisplatin/5-fluorouracil) as the second-line therapy. Four months after initiating treatment, her general condition deteriorated, and the treatment was switched to palliative care. She died 5 months after initiating treatment.

\section{Discussion}

Our case highlights the occurrence of the adenoma-carcinoma sequence in a duodenal carcinoma based on histopathological evidence. In general, duodenal carcinomas account for $1 \%$ of all gastrointestinal carcinomas $[9,10]$. Limited studies have described the adenomacarcinoma sequence in the duodenum, which is a carcinogenic variant. The present case had no characteristics, such as a family history, suggesting an inherited disease; however, in such cases, it is necessary to confirm the presence of an inherited disease, such as FAP and Lynch syndrome. Therefore, in addition to histopathological evaluations, we performed a comprehensive gene analysis using next-generation sequencing. A subsequent genetic analysis revealed that the patient harbored a germline APC mutation [11]. Although the existence of the adenoma-carcinoma sequence in colon carcinomas of FAP patients is well-documented, the existence of the adenoma-carcinoma sequence in duodenal carcinomas of FAP patients remains controversial $[12,13]$.

There are multiple possibilities for the primary origin of carcinomas of the duodenum, such as duodenal, pancreatic, bile duct, and papillary carcinomas. Additionally, primary carcinoma of the duodenum can have various causes. In particular, in duodenal adenocarcinomas with duodenal adenomas, it is extremely difficult to diagnose duodenal carcinomas owing to FAP in patients without a family history of FAP. Previous reports have suggested the presence of the adenoma-carcinoma sequence in small intestine carcinomas [14]. However, there are also reports that the adenoma-carcinoma sequence in small intestine carcinomas is extremely rare [15].

This case of an advanced duodenal adenocarcinoma in which an APC germline mutation was detected using next-generation sequencing, which has the characteristic of the adenomacarcinoma sequence, is important. Thus, a comprehensive gene analysis is important for rare cases having a possibility of the presence of the adenoma-carcinoma sequence in duodenal carcinomas.

\section{Karger'=}




\section{Case Reports in Gastroenterology}

\begin{tabular}{l|l}
\hline Case Rep Gastroenterol 2021;15:62-69 \\
\hline DOI: 10.1159/000510919 & $\begin{array}{l}\text { ○ 2021 The Author(s). Published by S. Karger AG, Basel } \\
\text { www.karger.com/crg }\end{array}$ \\
\hline
\end{tabular}

Yoshida et al.: Next-Generation Sequencing for Non-Ampullary Duodenal Carcinoma Suggesting the Existence of an Adenoma-Carcinoma Sequence

\section{Statement of Ethics}

This study was approved by the Research Ethics Committee of Kosei Hospital, Japan. Informed consent for publication including images was obtained from the patient's family. Research was conducted ethically in accordance with the World Medical Association Declaration of Helsinki.

\section{Conflict of Interest Statement}

The authors have no conflicts of interest to declare.

\section{Funding Sources}

No source of funding was received for this work.

\section{Author Contributions}

Yohei Kojima cooperated as an instructor. Takashi Nikaido and Kouki Ohtsuka provided technical support and advice. Ryusuke Shimada, Hidesato Tanabe, Koichi Tabei, Osamu Yanagida, Hiroaki Ohnishi, Nobutsugu Abe, Tadakazu Hisamatsu, and Shinichi Takahashi provided advice.

\section{References}

1 Leslie A, Carey FA, Pratt NR, Steele RJ. The colorectal adenoma-carcinoma sequence. Br J Surg. 2002 Jul;89(7):845-60.

2 Hamilton SR. The adenoma-adenocarcinoma sequence in the large bowel: variations on a theme. J Cell Biochem Suppl. 1992;16G S16G:41-6.

3 Kaiser A, Jurowich C, Schönekäs H, Gebhardt C, Wünsch PH. The adenoma-carcinoma sequence applies to epithelial tumours of the papilla of Vater. Z Gastroenterol. 2002 Nov;40(11):913-20.

4 Preston SL, Leedham SJ, Oukrif D, Deheregoda M, Goodlad RA, Poulsom R, et al. The development of duodenal microadenomas in FAP patients: the human correlate of the Min mouse. J Pathol. 2008 Feb;214(3):294-301.

5 Sellner F. Investigations on the significance of the adenoma-carcinoma sequence in the small bowel. Cancer. 1990 Aug;66(4):702-15.

6 Thiruvengadam SS, O'Malley M, LaGuardia L, Lopez R, Wang Z, Shadrach BL, et al. Gene expression changes accompanying the duodenal adenoma-carcinoma sequence in familial adenomatous polyposis. Clin Transl Gastroenterol. 2019 Jun;10(6):e00053.

7 Stormorken AT, Berg T, Norum OJ, Hølmebakk T, Aaberg K, Steigen SE, et al. APC mosaicism in a young woman with desmoid type fibromatosis and familial adenomatous polyposis. Fam Cancer. 2018 0ct;17(4):539-43.

8 Toyooka M, Konishi M, Kikuchi-Yanoshita R, Iwama T, Miyaki M. Somatic mutations of the adenomatous polyposis coli gene in gastroduodenal tumors from patients with familial adenomatous polyposis. Cancer Res. 1995 Jul;55(14):3165-70.

9 Alwmark A, Andersson A, Lasson A. Primary carcinoma of the duodenum. Ann Surg. 1980 Jan;191(1):13-8.

10 Zenali M, Overman MJ, Rashid A, Broaddus RB, Wang H, Katz MH, et al. Clinicopathologic features and prognosis of duodenal adenocarcinoma and comparison with ampullary and pancreatic ductal adenocarcinoma. Hum Pathol. 2013 Dec;44(12):2792-8.

11 Half E, Bercovich D, Rozen P. Familial adenomatous polyposis. Orphanet J Rare Dis. 2009 Oct;4(1):22.

\section{Karger'=}




\section{Case Reports in Gastroenterology}

\begin{tabular}{l|l}
\hline Case Rep Gastroenterol 2021;15:62-69 \\
\hline DOI: 10.1159/000510919 & $\begin{array}{l}\text { @ 2021 The Author(s). Published by S. Karger AG, Basel } \\
\text { www.karger.com/crg }\end{array}$ \\
\hline
\end{tabular}

Yoshida et al.: Next-Generation Sequencing for Non-Ampullary Duodenal Carcinoma Suggesting the Existence of an Adenoma-Carcinoma Sequence

12 Spigelman AD, Talbot IC, Penna C, Nugent KP, Phillips RK, Costello C, et al.; The Leeds Castle Polyposis Group (Upper Gastrointestinal Committee). Evidence for adenoma-carcinoma sequence in the duodenum of patients with familial adenomatous polyposis. J Clin Pathol. 1994 Aug;47(8):709-10.

13 Labib PL, Goodchild G, Turbett JP, Skipworth J, Shankar A, Johnson G, et al. Endoscopic ultrasound in the assessment of advanced duodenal adenomatosis in familial adenomatous polyposis. BMJ Open Gastroenterol. 2019 Sep;6(1):e000336.

14 Nakano Y, Adachi Y, Okamoto H, Kiyama Y, Koyama T, Nakamura SI, et al. Adenocarcinoma with adenoma in the jejunum suggesting an adenoma-carcinoma sequence in the small bowel: A case report. Oncol Lett. 2014 Aug;8(2):633-6.

15 Kojima Y, Ohtsuka K, Ohnishi H, Abe N, Furuse J, Watanabe T, et al. APC:T1556fs and STK11 mutations in duodenal adenomas and adenocarcinomas. Surg Today. 2018 Aug;48(8):765-72.
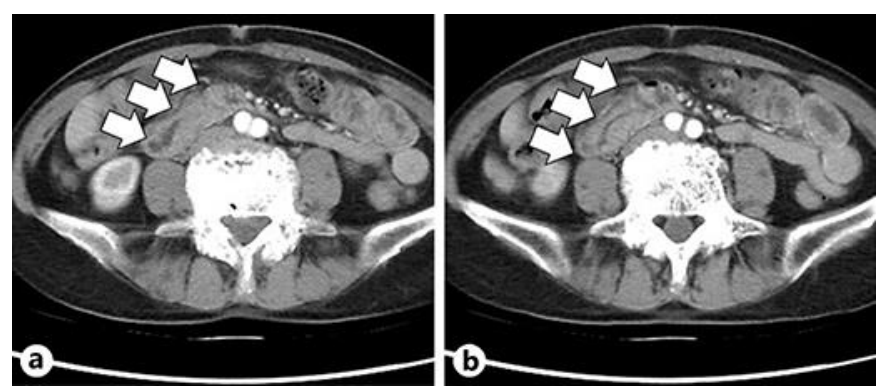

Fig. 1. Contrast-enhanced computed tomography. The two images show the height of the descending portion of the duodenum. The image on the right (b) is located $5 \mathrm{~mm}$ closer to the head than the image on the left (a). The descending portion of the duodenum showed circumferential wall thickening (arrows), with the head on the opposite side of the papilla of the neck, suggesting a neoplastic lesion.

\section{Karger'=}




\section{Gastroenterology}

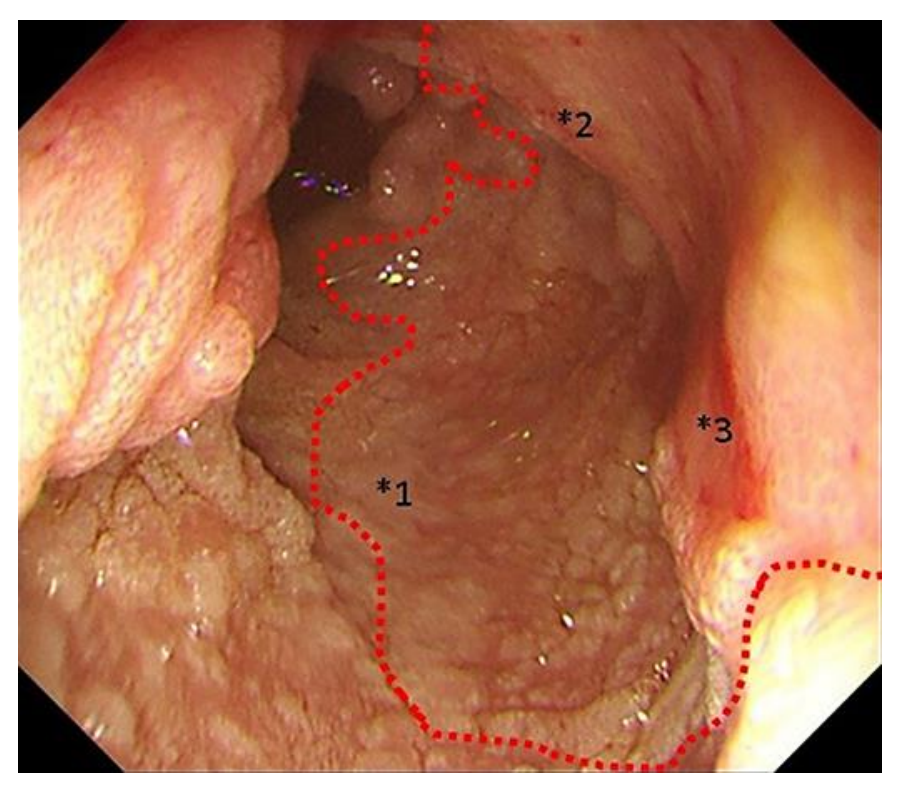

Fig. 2. Upper gastrointestinal endoscopy. Biopsies were performed at site No. 1-3. All biopsies were performed using samples from a series of lesions surrounded by the dotted red line. Biopsy No. 1 sample was taken from the white microprojections around the ulcer. Biopsy No. 2 sample was taken from the surrounding ridge with ulcerative redness. Biopsy No. 3 sample was taken from the top of the ulcerative lesion on the other side of the nipple. 


\section{Case Reports in Gastroenterology}
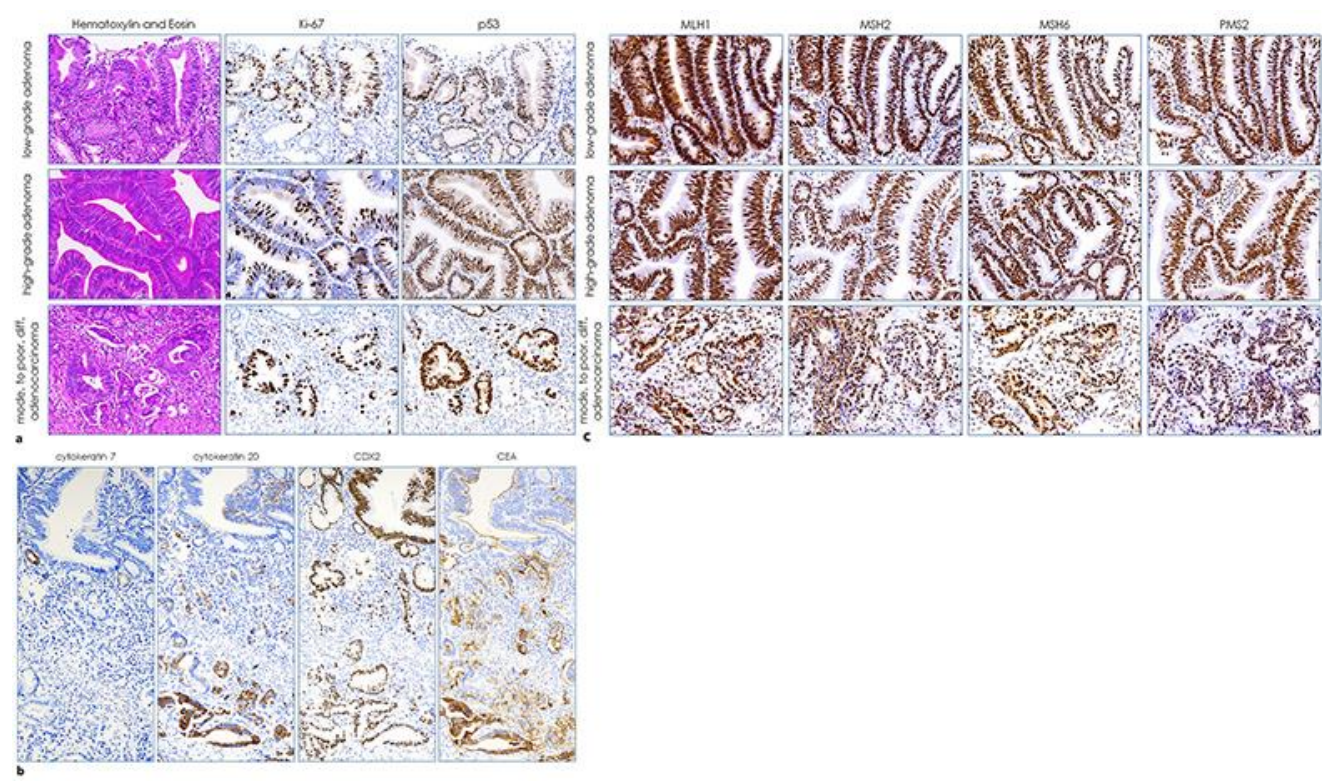

Fig. 3. Pathology and immunostaining results. a Microscopic analysis of the tumor. The upper row shows the results of biopsy No. 1, the middle row shows biopsy No. 2, and the lower row shows biopsy No. 3. The left column displays hematoxylin and eosin (H\&E) staining, the middle column shows expression of Ki-67, and the right column shows expression of p53. Biopsy No. 1 was diagnosed as a low-grade adenoma, biopsy No. 2 as a high-grade adenoma, and biopsy No. 3 as a moderate-to-poorly differentiated adenocarcinoma $(200 \times)$. b To rule out the possibility of metastasis or invasion from other primary sites, immunohistochemistry was performed for cytokeratin 7, cytokeratin 20, caudal-type homeobox (CDX) 2, and carcinoembryonic antigen (CEA). The tissue tested negative for cytokeratin 7 and positive for cytokeratin 20, CDX2, and CEA (100×). c Immunohistochemistry for human mutL homolog (MLH) 1, MSH2, MSH6, and postmeiotic segregation increased (PMS) 2 was performed in all three biopsy samples. All of these proteins were expressed, indicating that the patient did not have Lynch syndrome (200x).

\section{Karger'=}

